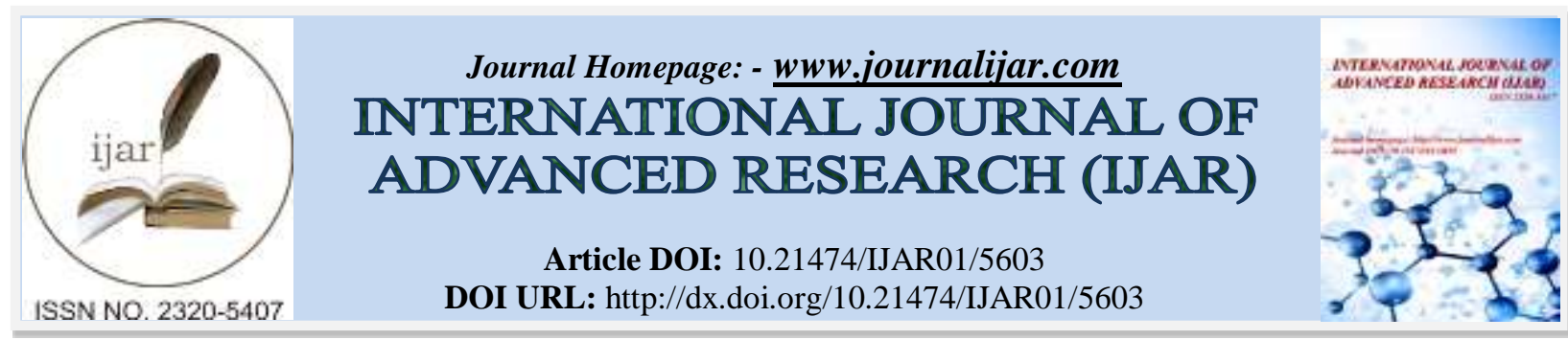

RESEARCH ARTICLE

\title{
COMPARATIVE STUDY BETWEEN REVASCULARIZATION (REGENERATION) AND MTA APEXIFICATION FOR NECROTIC IMMATURE PERMANENT ANTERIOR TEETH WITH OPEN APEX: A RANDOMIZED CONTROLLED TRIAL.
}

\author{
Amir Awies ${ }^{1}$, Angie Ghoniem ${ }^{2}$ and Alaa El-Baz ${ }^{3}$. \\ 1. Master degree student,faculty of Oral and Dental Medicine, Cairo University. \\ 2. Professor of Endodontics,faculty of Oral and Dental Medicine, Cairo University. \\ 3. Associate Professor of Endodontics, faculty of Oral and Dental Medicine, Cairo University.
}

\section{Manuscript Info \\ Manuscript History \\ Received: 12 August 2017 \\ Final Accepted: 14 September 2017 \\ Published: October 2017}

\section{Key words:-}

Open apex, regeneration, MTA apexification, revascularization.

\begin{abstract}
Introduction: The purpose of the study was to compare the effectiveness of pulp revascularization and MTA apexification in the treatment of necrotic anterior teeth with periapical abscess.

Methods: twenty-two patients, each with necrotic immature permanent anterior teeth were randomly divided into 2 groups (Group A apexification and group B regeneration) 11 patient per each group. A triantibiotic paste (metronidazole, ciprofloxacin and doxycycline) was used to disinfect the canal for 21 days. MTA plug was used for apexification for group A. Blood clot regeneration was used for the group B. The patients were recalled periodically for follow up.

Results: The regeneration group showed better results in, increase in root length, increase in dentin thickness in $\mathrm{mm}$, and in percentage, while MTA apexification group showed better results in decrease in apical diameter in millimeter.

Conclusions: Both regeneration and MTA apexification are reliable procedures for treating necrotic immature anterior teeth with open apices.
\end{abstract}

Copy Right, IJAR, 2017,. All rights reserved.

\section{Introduction:-}

Treatment of necrotic immature teeth has always been a challenge in endodontics ${ }^{(1)}$. The absence of normal apical constriction of the root canal complicates the management of the root canal filling treatment ${ }^{(2)}$. This feature makes instrumentation of the canal wall difficult and hinders the formation of an adequate apical stop ${ }^{(3)}$. The clinical protocol for immature teeth with infected root canal systems was termed 'apexification' and involved placing calcium hydroxide as an intra-canal medicament to eliminate the intra-radicular infection and induce an apical barrier over time. An alternative technique is placement of mineral trioxide aggregate (MTA) which acts as an artificial barrier. However, one of the disadvantages of these apexification techniques that it did not allow for continued root formation ${ }^{(4)}$.

The ideal treatment to obtain further root development would be revascularization ${ }^{(5)}$. Regenerative endodontic procedures have been growing with $96 \%$ of endodontists being willing to incorporate regenerative therapies into the treatments ${ }^{(6)}$. the advantages of this treatment modality, which resulted in radiographically apparent normal maturation of the entire root versus formation of a calcific barrier at the apex after conventional calcium hydroxide- 
induced apexification ${ }^{(1)}$. Regeneration was recommended by many researchers ${ }^{(5-8)}$ to be the treatment of choice in necrotic teeth with open apices rather than MTA apexification due to its superior results in increasing crown-to-root ratio, root dentinal wall thickness and complete root formation with apical closure.

\section{Materials and methods:-}

The trial design of this study is a prospective, 2-arm, 1:1, parallel, randomized, clinical trial (RCT). 176 cases were calculated for the 8 research team operators, 22 cases per each operator. The inclusion criteria included having asymptomatic and/or symptomatic immature necrotic upper and/or lower anterior teeth, age ranging 8-17 years and all were medically free. The patients were selected from outpatient clinic of Pediatric Dentistry Department, Faculty of Oral and Dental Medicine, Cairo University, Egypt. Medical, dental and trauma histories were obtained and the pulpal diagnosis for each tooth was based on the chief complaint and the negative response to both cold thermal test using ethyl chloride spray and hot gutta-percha cone test. In addition, periapical radiograph and periapical status was assessed. The patients were instructed basically to take abroad spectrum antibiotic from penicillin group (EMOXCLAV $312 \mathrm{mg} \mathrm{t}$. d. s.) for 3 days before the procedure and no analgesics. The patients fill the modified visual analogue scale (VAS) (figure 1). This was done preoperatively and at 4, 12, 24 and 48 hours after first and second visits and during follow up visits on 1, 3, 6, and 9 months accurately.

In this study 22 patients were randomly divided into 2 groups (11 patients per each group), where treatment was completed in 2 visits.

First visit: A triple antibiotic paste was utilized in all teeth of both groups.

Second visit: Group A: Teeth were treated by MTA apexification. Group B: Teeth were treated by regeneration using blood clot formation.

Patients were anesthetized using 1.8-3.6 ml of mepivacaine without vasoconstrictor (Mepivacaine $\mathrm{HCl} \mathrm{3 \%}$ ) and isolated with rubber dam. Access preparation was made utilizing round bur and fine diamond stone. The canal was then irrigated with $20 \mathrm{ml}$ of $5.25 \%$ sodium hypochlorite. Then k- file size 15 was placed to determine the working length. The canals were dried with paper points and flowable composite was placed on the labial wall of the access cavity to minimize the incidence of crown discoloration.

The tri-antibiotic paste which consists of metronidazole, ciprofloxacin and doxycycline was prepared. The powder of the 3 antibiotics was then mixed with $3 \mathrm{ml}$ of distilled water till a creamy paste was obtained. The paste was carefully introduced into the canal $2 \mathrm{~mm}$ shorter than the working length with a suitable condenser, then the access cavity was sealed. The patient received the pain diary (Figure 1) and was instructed to fill in the required intervals $(4,12,24$, and 48 hours after the procedure $)$.

\section{$\underline{\text { Visual Analog Scale (VAS) }}$}

\section{Preoperative VAS:}

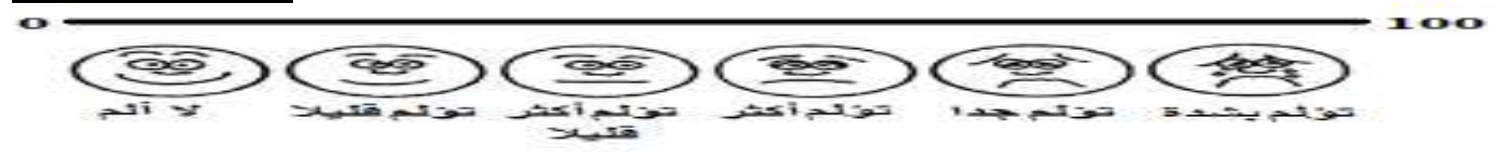

Postoperative VAS:

1-After 4 hours بعد ؛ ساعات

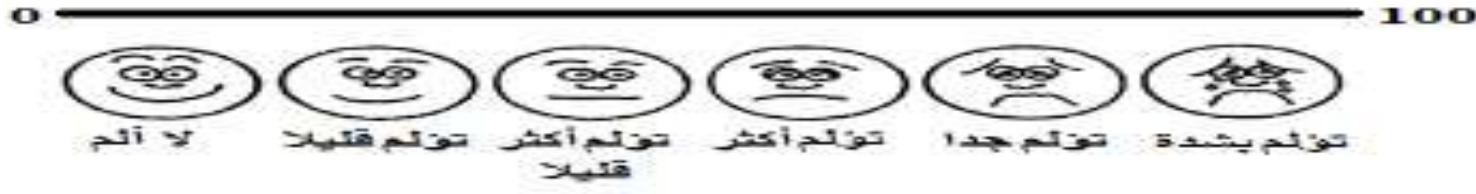

2-After 12 hours

بعد Y IT سـاعة 


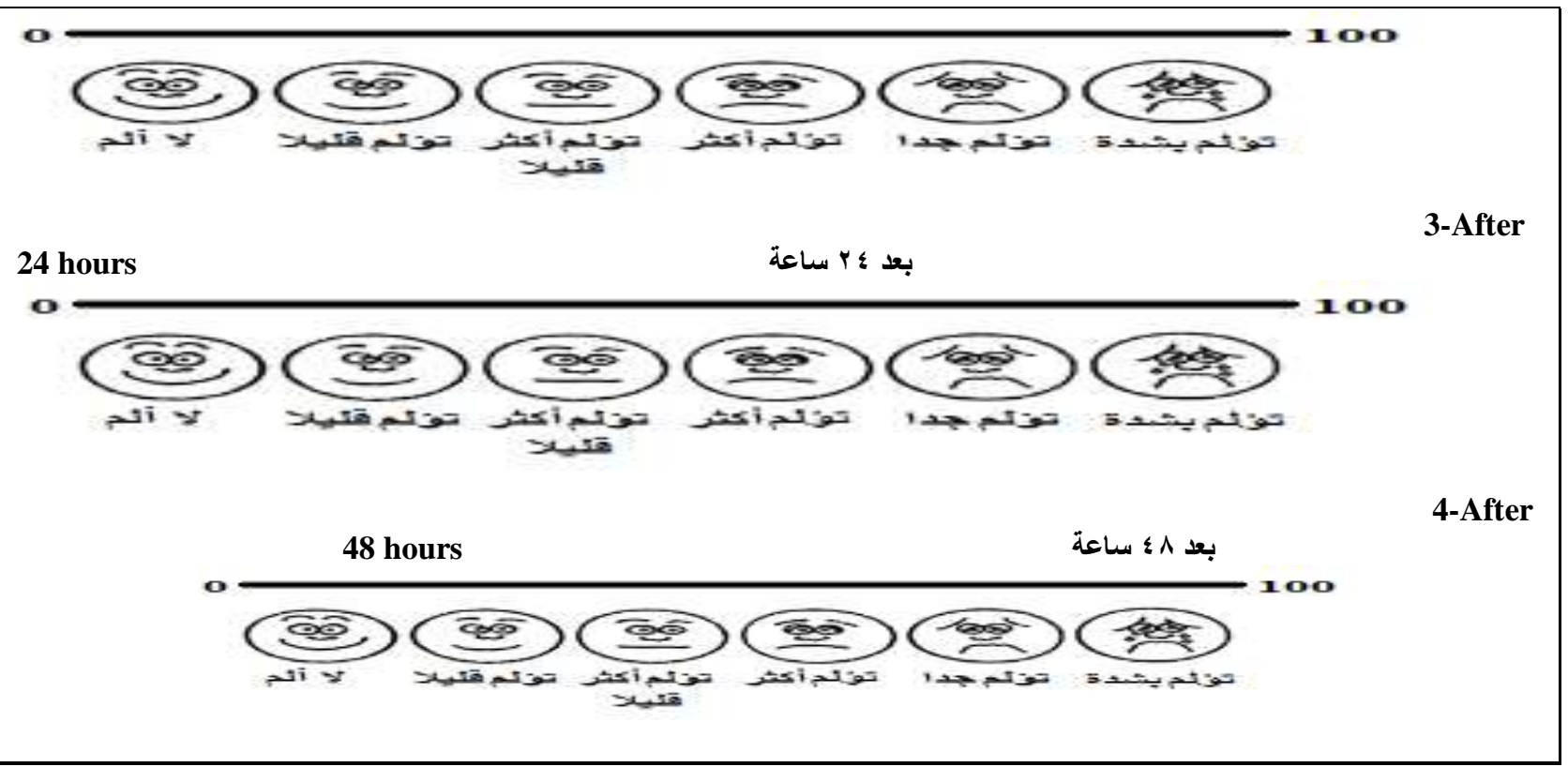

Figure (1):- Visual Analog Scale (VAS)

Second visit: After 3 weeks the patients were randomly divided into 2 groups:

Apexification group: (group A):-

After the tooth is anesthetized the access was reopened under rubber dam isolation and the canal was irrigated with $20 \mathrm{ml}$ of $5.25 \%$ sodium hypochlorite solution. The canal was dried with sterile paper points. Then the grey MTA was mixed and placed from the apex till the cemento-enamel junction (CEJ) is reached. The tooth is restored with double restoration glass ionomer and composite resin.

\section{Regeneration group: (group B):-}

After the tooth is anesthetized the access was reopened under rubber dam isolation and the canal was irrigated with $20 \mathrm{ml}$ of $5.25 \%$ sodium hypochlorite solution. The canal was dried with sterile paper points. Then a sterile $\mathrm{k}$ - file was used to irritate the apical tissue until bleeding occurred Over 15 minutes period of time the blood was allowed to clot to a level of $3 \mathrm{~mm}$ below the cemento-enamel junction then $3 \mathrm{~mm}$ of grey MTA was placed. The tooth was restored using double restoration of glass ionomer and composite resin.

For both groups: The patient received the pain diary (figure 1) and was instructed to fill in the required intervals (4, 12,24 , and 48 hours after the procedure). Postoperative radiograph was taken for each patient at the end of the second visit which is considered as a baseline radiograph to measure the preoperative root length, dentinal wall thickness, and apical diameter.

For this study criteria of success included the degree of postoperative pain (1ry outcome) and resolution of apical pathosis clinically and radiographically (2ry outcome).

\section{Results:-}

30 patients were selected and 8 were excluded as they were not meeting the criteria of selection or declined to participate. 22 remaining patients were randomized as shown in flow chart (figure 2).

\section{I-Baseline data included:-}

The demographic data, there was no statically difference in the mean age and gender values $(\mathrm{p}=0.112)$ and $(\mathrm{p}=0.987)$ respectively.

Clinical and radiographic preoperative findings, there was no statistical significant difference in prevalence of between the two groups ( $p>0.05)$. 


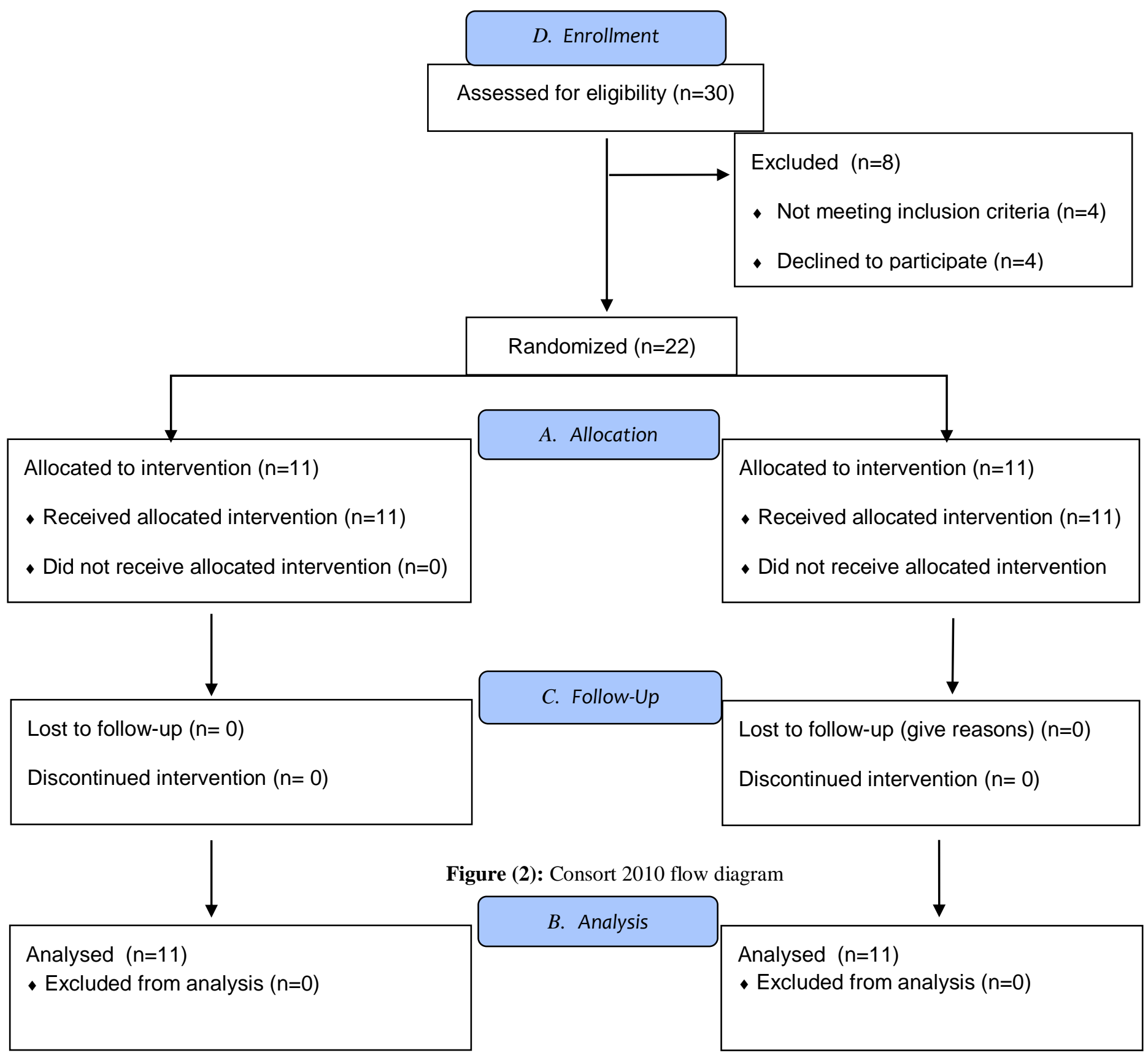

II-Pain results included:-

Comparison of VAS scores in the two groups:-

There was no statistical significant difference between the two groups in the mean VAS scores in the first, second, and follow up visits $\mathrm{p}>0.05$.

Differences between VAS scores over time within each group:-

Regarding the apexification group there was no statistical significant difference in the mean VAS scores for the first, second and follow up visits shown in table (1) and figure (3).

Regarding the regeneration group there was no statistical significant difference in the mean VAS scores for the first and follow up visits, while there was a significant statistical difference in the second visit found between mean VAS scores recorded after 4 hours and after 12 hours ( $\mathrm{p}=0.047$ ), after 12 hours and after 48 hours ( $\mathrm{p}=0.005$ ), and after 24 
hours and 48 hours $(\mathrm{p}=0.018)$ with the highest score recorded at 12 hours and the lowest score recorded at 48 hours shown table (1) and figure (3).

\begin{tabular}{|c|c|c|}
\hline Groups & Apexification (A) & Regenerative (B) \\
\hline Time & Mean \pm SD & Mean \pm SD \\
\hline \multicolumn{3}{|c|}{ Pre-operative } \\
\hline & $9.48 \pm \mathbf{1 0 . 2 3}$ & $9.35 \pm \mathbf{9 . 9 3}$ \\
\hline \multicolumn{3}{|c|}{ First visit } \\
\hline 4hrs & $22.69 \pm \mathbf{2 9 . 0 2}$ & $17.51 \pm \mathbf{1 5 . 0 4}$ \\
\hline 12hrs & $25.56 \pm 22.72$ & $20.41 \pm \mathbf{1 9 . 9 7}$ \\
\hline 24hrs & $19.27 \pm \mathbf{1 7 . 3 2}$ & $13.18 \pm \mathbf{1 4 . 9 5}$ \\
\hline 48hrs & $7.20 \pm 7.62$ & $7.29 \pm 7.59$ \\
\hline p-value & $0.122 \mathrm{~ns}$ & $0.190 \mathrm{~ns}$ \\
\hline \multicolumn{3}{|c|}{ Second visit } \\
\hline 4hrs & $20.75 \pm \mathbf{3 1 . 8 1}$ & $18.39 \pm \mathbf{2 0 . 4 6}$ \\
\hline 12hrs & $24.89 \pm 25.67$ & $36.59 \pm \mathbf{2 1 . 9 3}$ \\
\hline 24hrs & $26.93 \pm 27.77$ & $28.62 \pm \mathbf{2 6 . 5 7}$ \\
\hline 48hrs & $11.43 \pm \mathbf{1 1 . 2 6}$ & $9.33 \pm \mathbf{1 0 . 1 4}$ \\
\hline$p$-value & $0.152 \mathrm{~ns}$ & $0.004 *$ \\
\hline \multicolumn{3}{|c|}{ Follow up } \\
\hline 1 stm & $15.57 \pm \mathbf{2 1 . 2 1}$ & $9.45 \pm \mathbf{9 . 8 8}$ \\
\hline $3 \mathrm{~m}$ & $15.40 \pm \mathbf{2 4 . 6 0}$ & $8.61 \pm 12.31$ \\
\hline $6 \mathrm{~m}$ & $18.72 \pm \mathbf{2 5 . 7 5}$ & $12.34 \pm \mathbf{1 7 . 8 0}$ \\
\hline $9 m$ & $21.86 \pm \mathbf{2 9 . 0 7}$ & $15.31 \pm 27.44$ \\
\hline $12 \mathrm{~m}$ & $0.00 \pm \mathbf{0 . 0 0}$ & $0.00 \pm \mathbf{0 . 0 0}$ \\
\hline p-value & $0.100 \mathrm{~ns}$ & $0.300 \mathrm{~ns}$ \\
\hline
\end{tabular}

Table (1):- Mean and standard deviation (SD) values of the VAS scores and results of Friedman test for VAS scores within the two groups (A and B)

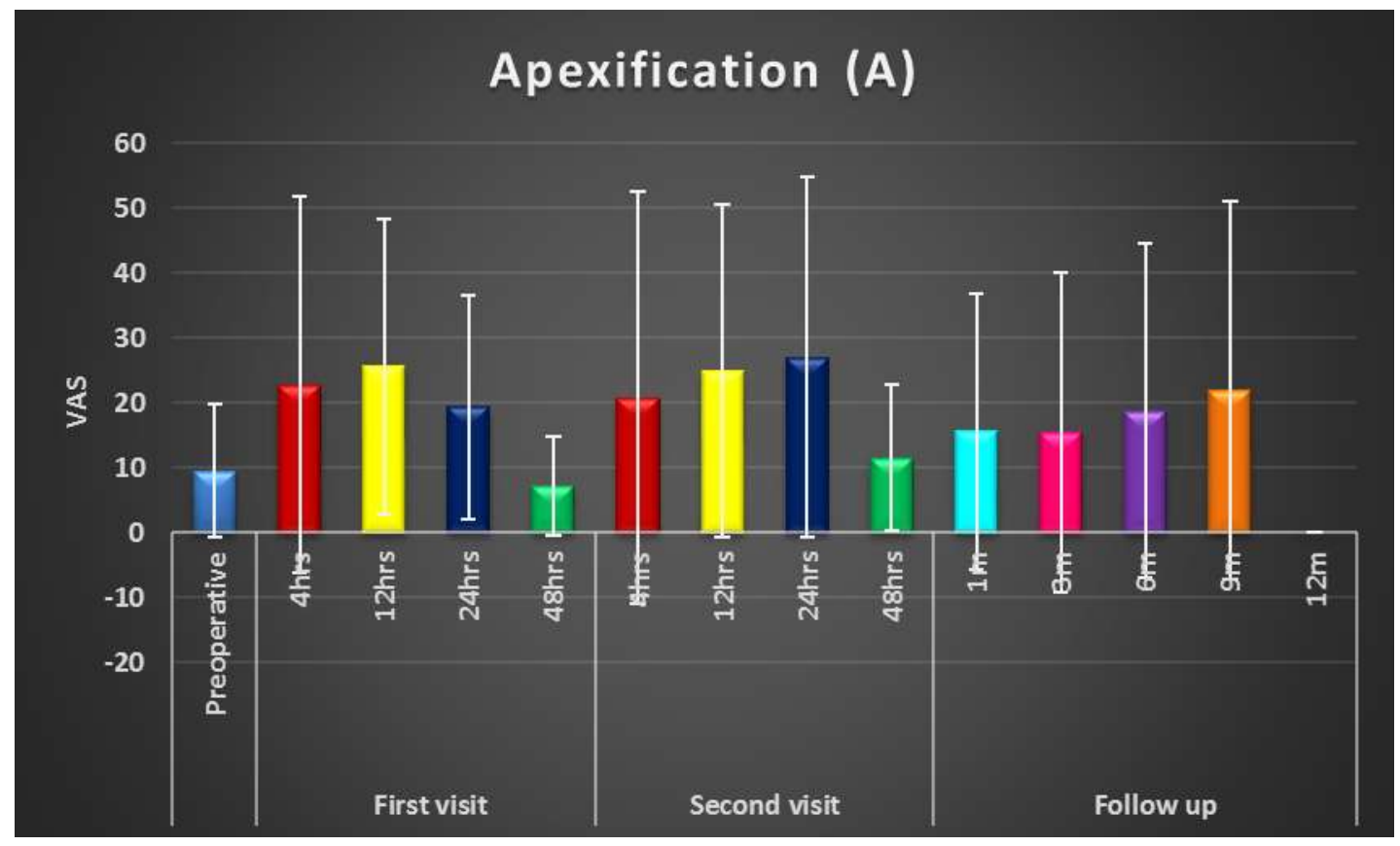

(A) 


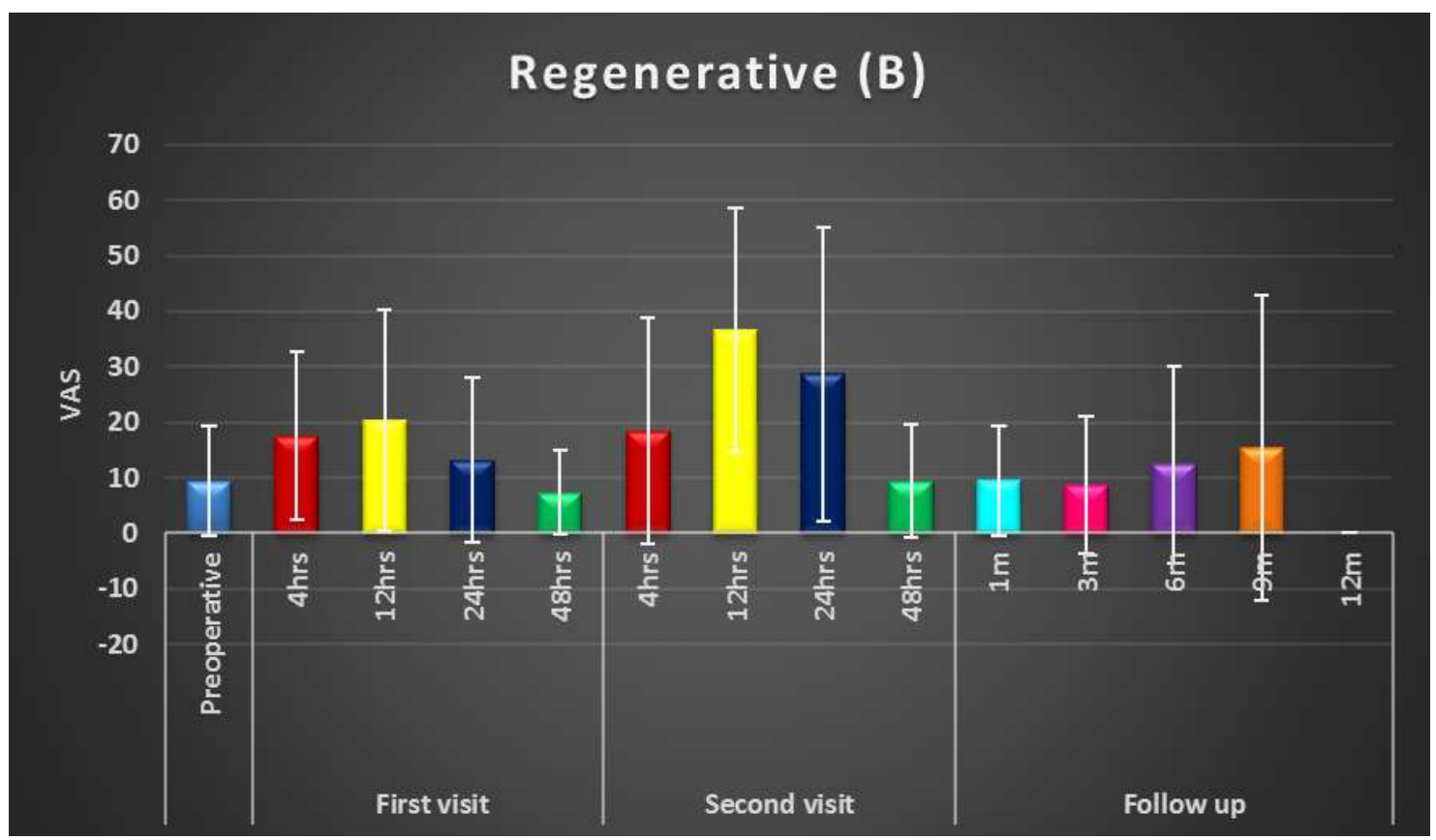

(B)

Figure (3):- Representing mean and standard deviation (SD) values of VAS scores over time in each group.

\section{III-Rate of success:-}

Regeneration group (B) showed a higher rate of success than apexification group (A). Where mean values of pain after 9 months in regeneration group (B) $(15.31 \pm 27.44)$ was lower than apexification group (A) (21.86 \pm 29.07$)$, percentage of periapical radiolucency reduction in regeneration group (B) $(90.9 \%)$ was higher than apexification group (A) (63.6\%), and percentage of healing of swelling in regeneration group (B) $(81.8 \%)$ was higher than apexification group (A) (72.7 \%) as shown table (2) and figure (4).

\begin{tabular}{|c|c|c|c|c|c|c|}
\hline \multirow[t]{2}{*}{ Groups } & \multirow[t]{2}{*}{ Time } & \multirow{2}{*}{\multicolumn{2}{|c|}{$\begin{array}{c}\text { Apexification (A) } \\
\text { Mean } \pm \text { SD }\end{array}$}} & \multirow{2}{*}{\multicolumn{2}{|c|}{$\begin{array}{c}\text { Regeneration }(B) \\
\text { Mean } \pm \text { SD }\end{array}$}} & \multirow[t]{2}{*}{$P$ value } \\
\hline & & & & & & \\
\hline \multirow{3}{*}{ Pain } & Preoperative & \multirow{2}{*}{\multicolumn{2}{|c|}{$\frac{9.57 \pm \mathbf{1 0 . 1 0}}{2105+\mathbf{2 0 0 0}}$}} & \multirow{2}{*}{\multicolumn{2}{|c|}{$\begin{array}{c}9.40 \pm \mathbf{9 . 8 8} \\
15.42 \pm \mathbf{2 7 . 4 0}\end{array}$}} & $0.949 \mathrm{~ns}$ \\
\hline & 9 Months & & & & & $0.519 \mathrm{~ns}$ \\
\hline & & Number & $\%$ & No & $\%$ & \\
\hline \multirow[t]{2}{*}{ Radiolucency before treatment } & No & 1 & 9.1 & 4 & 36.4 & \\
\hline & Yes & 10 & 90.9 & 7 & 63.6 & \\
\hline \multirow[t]{2}{*}{ Radiolucency after treatment } & Diseased & 4 & 36.4 & 1 & 9.1 & \\
\hline & Healed & 7 & 63.6 & 10 & 90.9 & \\
\hline \multirow[t]{2}{*}{ Swelling before treatment } & No & 5 & 45.5 & 6 & 54.5 & \\
\hline & Yes & 6 & 54.5 & 5 & 45.5 & \\
\hline \multirow[t]{2}{*}{ Swelling after treatment } & Diseased & 3 & 27.3 & 2 & 18.2 & \\
\hline & Healed & 8 & 72.7 & 9 & 81.8 & \\
\hline
\end{tabular}

Table (2):- The mean and standard deviation (SD) of pain VAS records, number, percentage of radiolucency and swelling found in each group (A and $\mathrm{B}$ ) before and after treatment. 


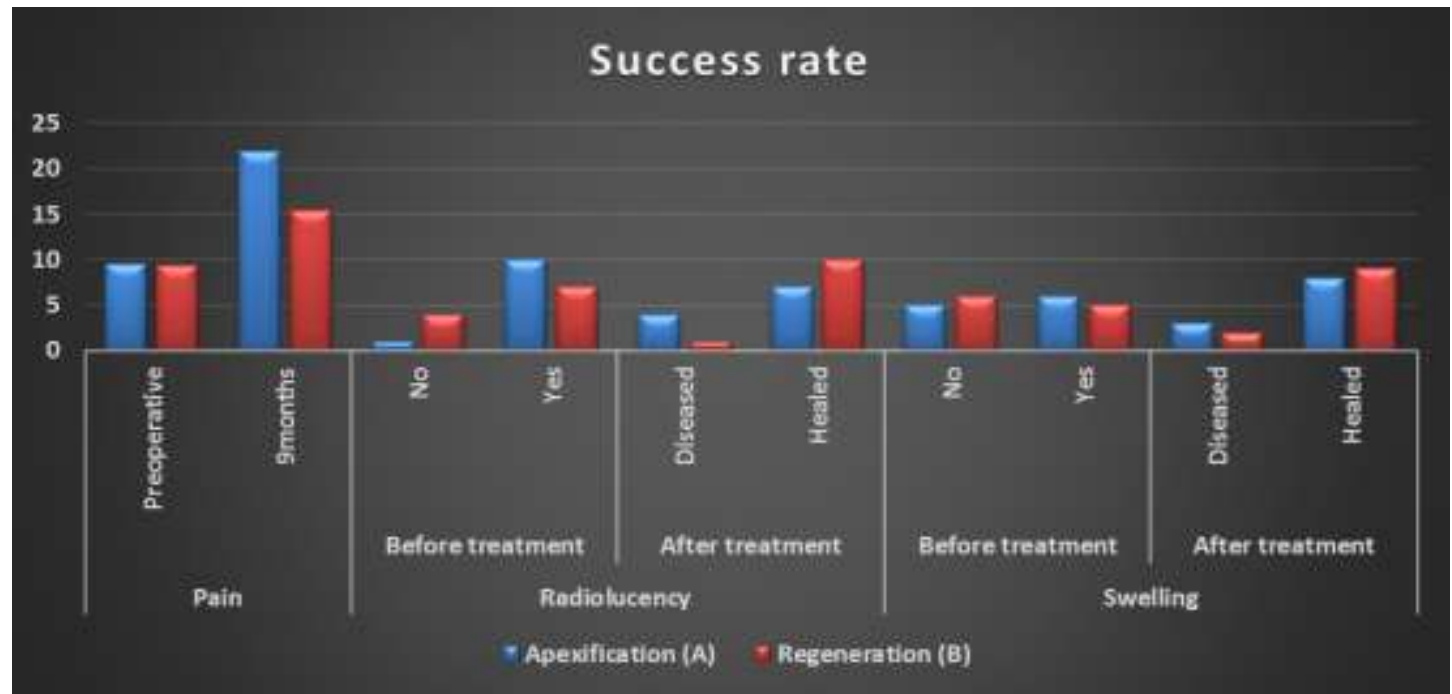

Figure (4):- The mean and standard deviation (SD) of pain VAS records, number, percentage of radiolucency, and swelling found in each group (A and B) before and after treatment.

\section{IV- Root length, dentin thickness and apical diameter in $\mathbf{m m}$ and percentage:-}

There was no statistical significant difference between apexification group (A) and regeneration group (B) in regards of increase root length, dentin thickness and apical diameter. Shown in table (3) and figure (5-7).

\begin{tabular}{|l|c|c|c|c|c|}
\hline \multirow{2}{*}{ Groups } & \multicolumn{2}{|c|}{ Apexification (A) } & \multicolumn{2}{c|}{ Regenerative (B) } & \multirow{2}{*}{ P value } \\
\cline { 2 - 5 } Time & Mean \pm SD & \% & Mean \pm SD & \% & \\
\hline Increase in Root length & $1.37 \pm 0.94$ & $6.17 \pm 11.36$ & $1.40 \pm 0.55$ & $5.00 \pm 9.72$ & $0.579 \mathrm{~ns}$ \\
\hline Increase in Dentin thickness & $0.92 \pm 0.49$ & $4.65 \pm 13.66$ & $0.99 \pm 0.55$ & $6.07 \pm 25.54$ & $0.912 \mathrm{~ns}$ \\
\hline Decrease in Apex diameter & $1.30 \pm 0.72$ & $32.66 \pm 54.49$ & $1.11 \pm 0.55$ & $26.06 \pm 26.71$ & $0.631 \mathrm{~ns}$ \\
\hline
\end{tabular}

Table (3):- Mean values and standard deviation (SD) of increase in root length and dentin thickness, and decrease in apical diameter in $\mathrm{mm}$ and percentage. Results of independent sample $\mathrm{t}$ test between the two groups (A and B).

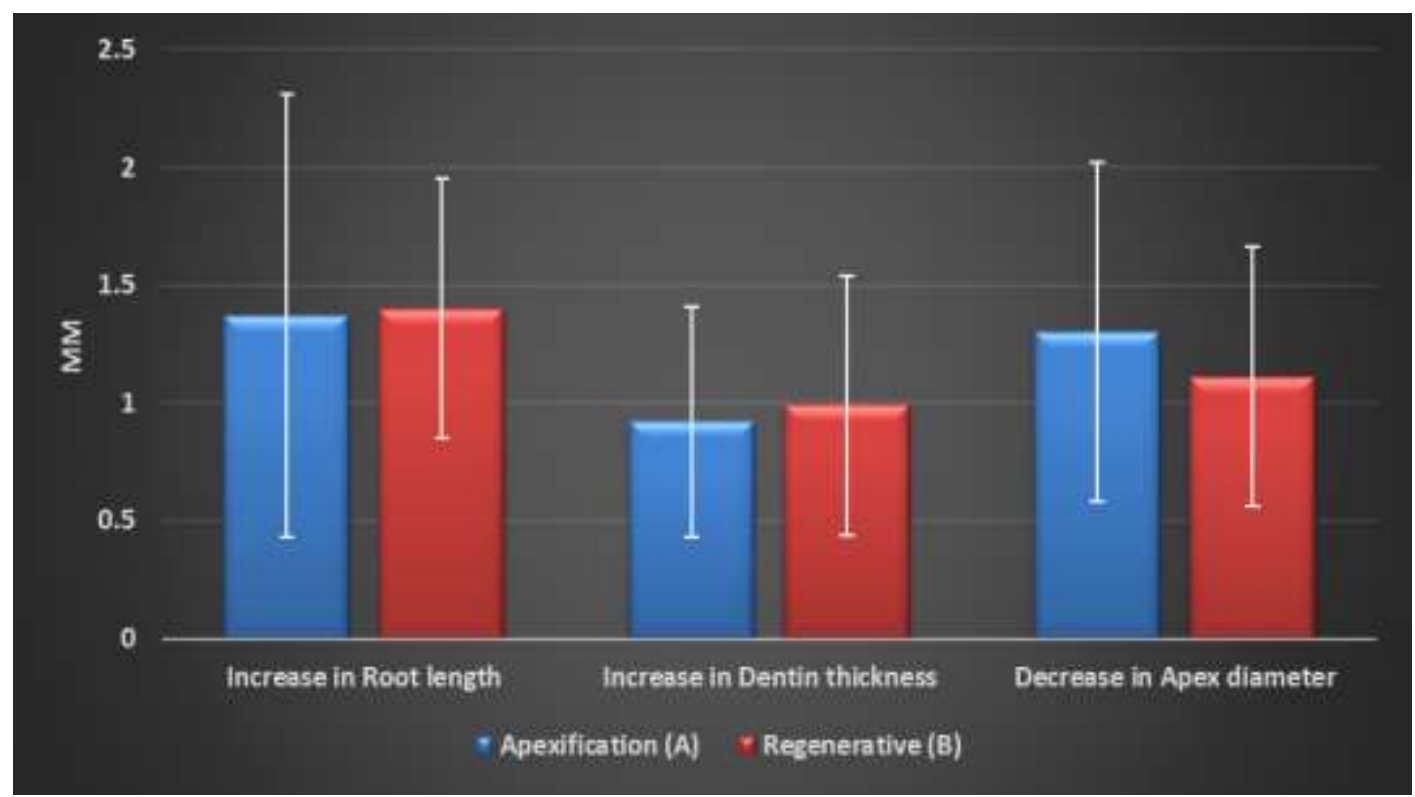

Figure (5):- Increase in root length, increase in dentin thickness and decrease in apical diameter in $\mathrm{mm}$. 


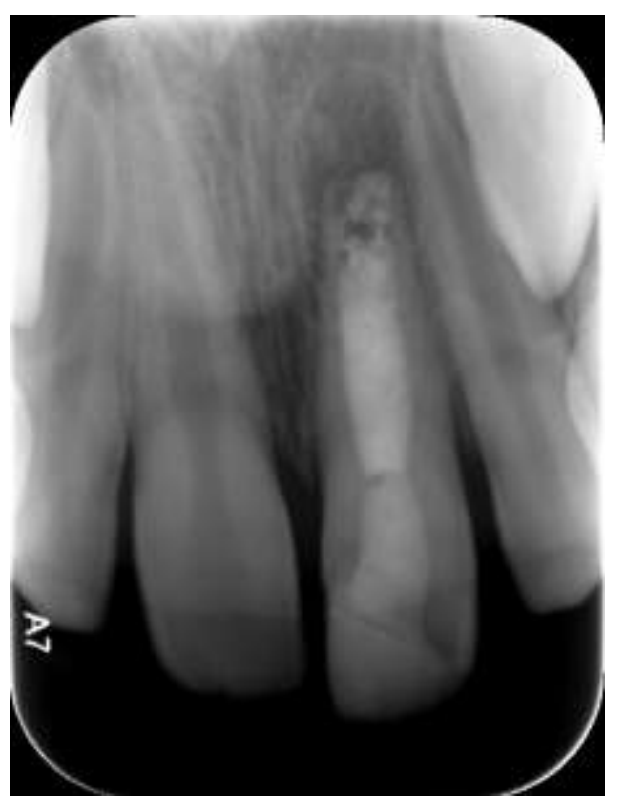

(A)

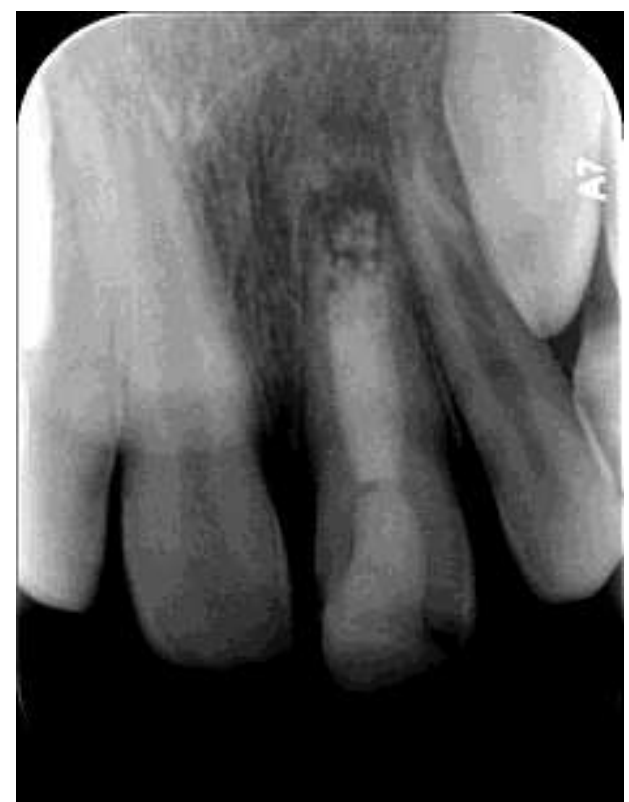

(B)

Figure (6):- Radiograph showing successful case of MTA apexification group with no change in root length and no change in dentin thickness but with decrease in periapical radiolucency where (A) is the baseline radiograph and (B) is the radiograph after 9 months.

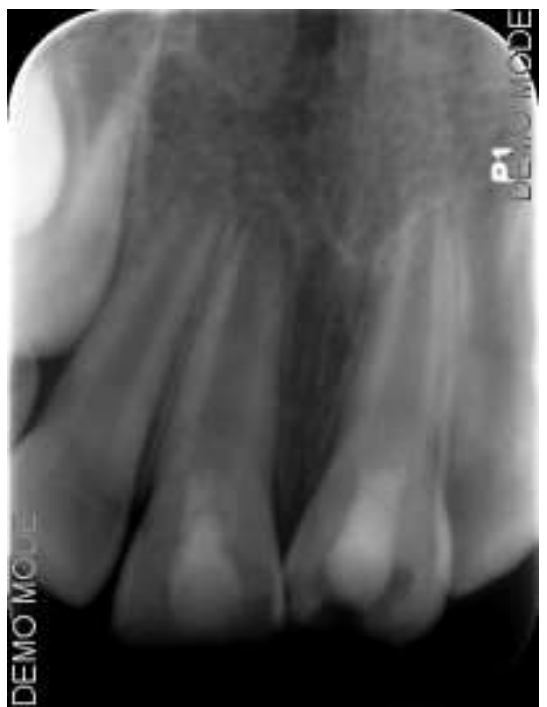

(A)

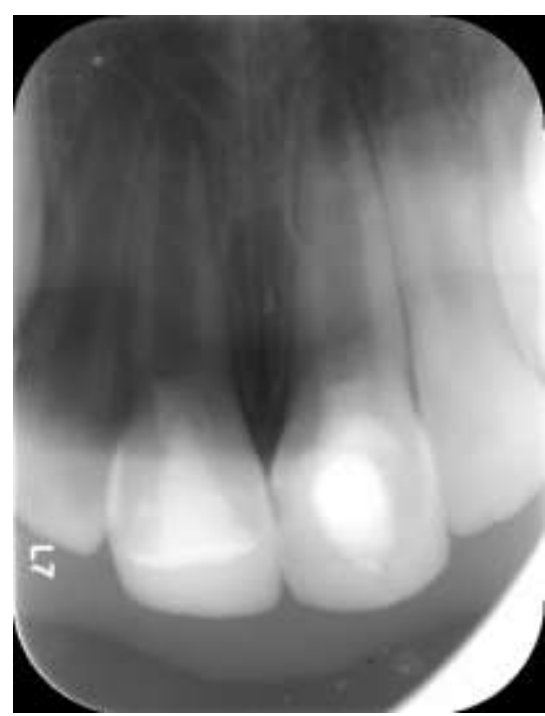

(B)

Figure (7):- Radiograph of 2 cases treated with regeneration group showing a little change in apical diameter with no change in root canal length and slight increase in root canal thickness where (a) is the baseline radiograph and (b) is the 9 months follow up.

\section{Discussion:-}

Mineral trioxide aggregate (MTA) have been proposed in 1 or 2-step apexification procedure, to create an artificial apical barrier that allows the compaction of obturating material and the placement of coronal restoration ${ }^{(9)}$. It has shown to produce good sealability, biocompatibility and apical hard tissue formation with significantly greater consistency ${ }^{(10,11)}$. MTA apexification still didn't address the unfavorable crown-to-root ratio and the weakness of the root due to thin dentin thickness ${ }^{(12,13)}$.

Regeneration was proposed by the literature as technique to provide the proper environment for continuing the root formation thus increasing root length and dentin thickness and decreasing the apical foramen diameter ${ }^{(1,8)}$. The 
concept of the revascularization techniques is based on the differentiation of the vital stem cells into secondary odontoblasts, ultimately allowing dentin deposition ${ }^{(9)}$. Jeeruphan et al ${ }^{(9)}$ and Nagy et al ${ }^{(14)}$ have found that the MTA apical plugging and the regenerative procedure were successful treatment options regarding the apical closure. Therefore, this study was conducted to evaluate and compare two different protocols for the treatment of immature permanent anterior teeth with pulp necrosis and apical pathosis.

In the present study, the parents and the patients were informed about the appointments, the possible adverse effects of the procedure (e.g. possibility of discoloration, pain and/or swelling after the procedure and that there may be a lack of response to treatment) and questioned regarding allergies to antibiotics used in the triple antibiotic paste ${ }^{(15)}$.

Disinfection of the canal and eradication of infection is a crucial key for the success of regeneration and MTA apexification. Usually this is achieved by mechanical instrumentation and chemical disinfection with irrigation and intracanal medicaments ${ }^{(5,16)}$. In this study mechanical instrumentation was avoided in both groups using only chemical disinfection (non-instrumentation disinfection) by triple antibiotic paste (TAP) and irrigation by $\mathrm{NaOCl}$ solution as suggested by Trope ${ }^{(17)}$ in 2008, Shin et al ${ }^{(18)}$ in 2009, Thomson and Kahler ${ }^{(4)}$ in 2010.

Twenty $\mathrm{ml}$ of $5.25 \% \mathrm{NaOCl}$ was selected for irrigation as suggested by many regenerative studies for its strong antibacterial properties and ability to dissolve the necrotic and organic tissues. On the contrary Harrison et al ${ }^{(19)}$ in 1978 recommended the dilution of $\mathrm{NaOCl}$ to prevent periapical inflammation and post-operative pain due to its cytotoxicity. Although Thomson and Kahler ${ }^{(4)}$ in $\mathbf{2 0 1 0}$ stated that $1 \% \mathrm{NaOCl}$ is just enough for the disinfection of the canal in regeneration, as higher concentration may decrease the vitality of the remaining vital dental stem cells.

In this study the TAP consisted of ciprofloxacin $200 \mathrm{mg}$, metronidazole $500 \mathrm{mg}$, and doxycycline $100 \mathrm{mg}$ with ratio 1:1:1 and mixed with sterile water ${ }^{(20,21)}$. Doxycycline was chosen over minocycline as it has the same antibiotic effect as concluded by Ritter et al ${ }^{\text {(22) }}$ in 2004, but with less discoloration effect as proved by Reynolds et al ${ }^{(21)}$ in 2008, Kim et al ${ }^{(22)}$ in 2010. Discoloration was further decreased in this study by coating the walls of access cavity by flowable composite prior to the application of TAP.

In the apexification technique, a 3-5mm of MTA was used as a root-end filling material to provide an apical barrier to enhance the healing of periodontal tissues and promote the regeneration of periradicular tissues to an almost normal condition ${ }^{(12,22)}$.

In the regeneration technique, the MTA was chosen to be placed directly over the blood clot to provide an effective coronal seal due to its biocompatibility with adjacent pulp tissue, induction of cell proliferation, sustained high $\mathrm{pH}$ and exceptional marginal adaptation ${ }^{(19)}$.

In the Regeneration group bleeding was initiated using K-files as stated by Reynolds et al ${ }^{(\mathbf{2 1 )}}$ in $\mathbf{2 0 0 8}$. The K-file is used to irritate the apical tissues with sharp strokes until bleeding occurs in the canal space to act as a biological scaffold.

In this study the primary and secondary outcomes were assessed. The primary outcome was resolution of pain and swelling clinically and periapical radiolucencies radiographically. Modified Visual Analogue Scale (VAS) was used to evaluate pain intensity. In this study pain assessment was done preoperatively, after 4, 12, 24, and 48 hours.

In both groups radiographic paralleling technique with XCP, prefabricated acrylic stent and an image plate that was interpreted by Digora were used to produce a baseline radiograph and postoperative ones in the recall visits after 1 , 3, 6 and 9 months. This provides an accurate comparison of periapical radiolucency.

In the present study the regeneration group (B) showed a statistical significant difference between pain VAS scores after 12 hours when compared to pain VAS scores at $\mathbf{4}$ and $\mathbf{4 8}$ hours where $p$ values were $p=0.047$ and $p=0.005$ respectively. Also a statistical significant difference was found when comparing the pain VAS scores after $\mathbf{2 4}$ hours and 48 hours where $p=0.018$. This could be due to the inflammation that resulted from the irritation of the periapical tissues by the $\mathrm{K}$ file used to draw fresh blood. 
Regarding pain VAS scores through follow up periods, there was no statistical significant difference neither between the two groups at all intervals nor over time within each group. This results were due to the resolution of infection, swelling, and periapical radiolucencies in both groups.

Regarding the secondary outcome, the percentage of healing of radiolucency $(90.9 \%)$ and swelling $(81.8 \%)$ were higher in regeneration group than in MTA apexification group (63.6\% and $72.7 \%$ respectively).

Although there was no statistical significant difference between apexification group and regeneration group regarding increase in root length and dentin thickness and decrease in apical diameter, regeneration group showed slightly better results in increase in root length. While apexification group showed better results in decrease in apical diameter.

\section{References:-}

1. Shah N, Logani A, Bhaskar U, Aggarwal V. Efficacy of revascularization to induce Apexification/Apexogensis in Infected, Nonvital Immature teeth: A pilot clinical study. J Endod2008; 34:919-25.

2. Asagry S, Ehsani S. MTA resorptions and periradicular healing in an open-apex incisor: A case report, Saudi Dent J 2012; 24:55-59.

3. D'Arcangelo C, D'Amario M, Chieti, L'Aquila. Use of MTA for orthograde obturation of nonvital teeth with open apices: report of two cases, Oral Surg.Oral Med Oral Pathol Oral Radiol. Endod 2007;104:98-101.

4. Thomson A, Kahler B. Regenerative endodontics biologically-based treatment for permanent teeth: a case report and review of literature. Aust Dent J. 2010;55:446-52.

5. Neha K, Kansal R, Garg P, Joshi R, Garg D, Grover HS. Management of immature teeth by dentin-pulp regeneration: A recent approach, Med Oral Patol Oral Cir Bucal 2011;16:997-04.

6. Garcia-Gody F, Murray PE. Recommendations for using regenerative endodontic procedures in permanent immature traumatized teeth, Dent Traumatol. 2012;28:33-41.

7. Iwaya S, Ikawa M, Kubota M. Revascularization of an immature permanent tooth with apical periodontitis and sinus tract. Dent Traumatol 2001;17:185-7.

8. BanchsF, Trope M. Revascularization of immature permanent teeth with apical periodontitis: new treatment protocol? J Endod 2004;30:196 -200.

9. Jeeruphan T, Jantarat J, Yanpiset K, Suwannapan L, Khewsawai P, Hargreaves KM. Mahidol study 1: comparison of radiographic and survival outcomes of immature teeth treated with either regenerative endodontic or apexification methods: a retrospective study. J Endod. 2012;38:1330-6.

10. Rafter M. Apexification: a review. Dent. Traumatol 2005;21:1-8

11. Simon S, Rilliard F, Berdal A and Machtou P. The use of mineral trioxide aggregate in one-visit apexification treatment: a prospective study. Int. Endod J 2007; 40:186-97.

12. Holden DT, Schwartz SA, Kirkpatrick TC, Svhindler WG. Clinical outcomes of artificial root-end barriers with mineral trioxide aggregate in teeth with immature apices. J Endod 2008;35:812-6.

13. Huang GT. Apexification: the beginning of its end, Int Endod J 2009;42:855-66.

14. Nagy MM, Tawfik HE, Hashem AA, Abu-Seida AM. Regenerative potential of immature permanent teeth with necrotic pulps after different regenerative protocols. J Endod. 2014;40:192-8.

15. Law A. Considerations for regeneration procedures. J Endod 2013;39:44- 56.

16. Trope M. Regenerative potential of dental pulp. J Endod 2008;34:13-17.

17. Shin S, Albert J, Mortman R. One step pulp revascularization of immature permanent tooth with chronic apical abscess: a case report. Int Endod J. 2009;42:1118-26.

18. Harrison JW, Svec TA, Baumgartner JC. Analysis of clinical toxicity of endodontic irrigants. J Endod 1978;4:611.

19. Reynolds K, Johnson JD and Cohenca N. Pulp revascularization of necrotic bilateral bicuspids using a modified novel technique to eliminate potential coronal discolouration: a case report. Int Endod J. 2009;42:84-92.

20. Kim JH, Kim Y, Shin SJ, Park JW, Jung IY. Tooth discoloration of immature permanent incisor associated with triple antibiotic therapy: a case report. J Endod. 2010;36:1086-91.

21. Ritter AL, Ritter AV, Murrah V, Sigurdsson A, Trope M. Pulp revascularization of implanted immature dog teeth after treatment with minocycline and doxycycline assessed by laser Doppler flowmetry, radiography and histology. Dent Traumatol 2004;20:75-84.

22. Witherspoon DE, Small JC, Regan JD and Nunn M. Retrospective analysis of open apex teeth obturated with mineral trioxide aggregate. J Endod. 2008;34:1171-6. 